\title{
Sociología
}

Bataillon, G. (2020). Democracia, cambio político, e incertidumbre: Lefort al encuentro de Maquiavelo. Revista de Sociología, 35(1), 69-79. doi:

\section{Democracia, cambio político, e incertidumbre: Lefort al encuentro de Maquiavelo}

\author{
[Democracy, political change, and uncertainty: Lefort meets Machiavelli]
}

\author{
Gilles Bataillon (D)
}

École des Haures Études en Sciences Sociales

\begin{abstract}
Resumen
La obra de Lefort, es valorada por sus aportes a la comprensión del fenómeno totalitario y su visión de la democracia como una experiencia social incierta y un lugar vacío donde la titularidad del poder es siempre transitoria. Su obra encuentra una importante fuente de inspiración en los escritos de Maquiavelo en los cuales trabajó durante veinte años logrando una de las interpretaciones más acabadas e innovadoras sobre el pensamiento del Florentino. Este trabajo desarrolla nuevas perspectivas de la lectura lefortiana de Maquiavelo, desde la génesis de su obra y sus aportes a la lectura del cambio político, que hoy cobra particular vitalidad para comprender la crisis de los regímenes democráticos liberales. Maquiavelo y Lefort toman nueva fuerza analítica para comprender las democracias como la posibilidad del cambio constante.
\end{abstract}

Palabras clave: Lefort, Maquiavelo, democracia, cambio político, conflicto.

\begin{abstract}
The work of Lefort is valued for its contributions to interpretations of the phenomenon of totalitarianism and for its view of democracy as an uncertain social experience and an empty space in which possession of power is always transitory. Lefort's work finds an important source of inspiration in the writings of Machiavelli, which he studied for 20 years, achieving one of the most complete and innovative interpretations of the Florentine's philosophy. This article develops new perspectives on the Lefortian reading of Machiavelli, beginning with the genesis of the French philosopher's work and his contributions to interpretation of political change, which today is of particular relevance to understanding the crisis of liberal democratic regimes. Machiavelli and Lefort acquire renewed analytical strength in a vision of democracy as the possibility for constant change.
\end{abstract}

Keywords: Lefort, Machiavelli, democracy, political change, conflict.

Contacto: La comunicación sobre este artículo debe ser enviada a Gilles Bataillon, email gilles.bataillon@ehess.fr

Nota: Parte de las ideas expuestas en este artículo fueron presentadas en la conferencia Política y Autoridad en la Obra de Claude Lefort realizada en el seminario del Núcleo Milenio Autoridad y Asimetrías de Poder realizado el 30 de septiembre de 2019 en la Universidad Diego Portales, Chile.

Agradecimientos: A Daniel Grimaldi por sus invaluables comentarios, sugerencias y apoyo en la elaboración de este trabajo. 


\section{INTRODUCCIÓN}

La crisis de la democracia y, más aún, de la democracia representativa, está hoy en el centro de atención en las ciencias sociales. El rumbo que ha tomado la vida política en Europa, Estados Unidos, y/o América Latina da crédito a esta tesis. Por ello es necesario preguntarse por las formas y modalidades de los desafíos a la democracia representativa y las alternativas a la misma; alternativas que oscilan entre los llamados a la democracia plebiscitaria -en la que los líderes populistas darían voz y sustancia a las clases populares ignoradas por las élites políticas-y las aspiraciones a diferentes formas de democracia directa. No obstante, la lectura de la política que se presenta en este trabajo es diferente. En él se realiza un análisis global de las sutiles y desconocidas reflexiones de Lefort (1972) sobre El Príncipe de Maquiavelo (1532|2006), pues sus reflexiones entregan pistas para interpretar de manera diferente las crisis que viven las democracias representativas. En el trabajo de Lefort (1997) consagrado a la idea de crisis de civilización, se analizan diversas posiciones sobre la percepción del "cambio de era" de varios filósofos, historiadores y escritores políticos Arendt, Strauss, Kosellek, Chateaubriand, Marx y Valéry. En dicho trabajo, Lefort planteó dos ideas fuertes que merecen nuestra especial atención. La primera, es que a lo largo del siglo XIX y a principios del XX, la idea de crisis parecía ser consustancial a la experiencia de la democracia moderna. La segunda, es que la importancia que se daba a este concepto en el debate público se refería a la dificultad, o mejor dicho, al "vértigo" hacia una forma de sociedad en la que las personas aceptan vivir bajo la incertidumbre total, y que ésta alimenta el deseo de libertad en medio de las tormentas. Al hacer esta observación, Lefort evitó ponerse en la posición de un intelectual-filósofo decidido a formular una "alternativa última" y por el contrario reafirmó las enseñanzas que había formulado en su largo comentario sobre los textos de Maquiavelo. En consecuencia, en este artículo quisiera retomar el trabajo más importante de Lefort (1972) sobre Maquiavelo centrándonos en particular en El Príncipe, la obra más conocida del pensador florentino (Maquiavelo 1532|2006). Cabe señalar que este es uno de los trabajos menos leídos y más voluminosos de Lefort, pero que a mi juicio revela grandes pistas sobre su obra y su particular lectura de Maquiavelo, que llena de luces para interpretar los problemas de la democracia contemporánea.

En la primera parte sintetizaré el punto de partida común a autores importantes para el análisis de la obra de Maquiavelo centrada en el realismo político, mostrando que Lefort va más allá de esta conocida interpretación. En la segunda parte señalaré los contextos en los cuales Lefort llega a Maquiavelo y se vuelve sensible a su lectura del conflicto de clases, y haré un paralelo sobre las condiciones en las cuales Maquiavelo escribe El Príncipe, las cuales merecen una especial atención para descifrar su 
mensaje en forma integral. En la tercera parte resumiré las principales ideas de Lefort fundamentadas en la obra de Maquiavelo, explicando su relevancia e influencia en su pensamiento sobre la democracia, el cambio político y la incertidumbre.

\section{MÁS ALLÁ DEL REALISMO POLÍTICO}

El Príncipe, es el libro menos comprendido de Maquiavelo dada la sutilidad con la cual se deslizan sus profundos análisis de la práctica de la política "al desnudo". Sin duda hay una visión común y generalizada donde autores como Aron (1993) y Morgenthau (1986) identifican en Maquiavelo el padre de la escuela realista, por comprender la política principalmente como una correlación de fuerzas. La ciencia política también ha rescatado de Maquiavelo una tradición fundadora de la disciplina por identificar un objeto de estudio claro y que se mantiene hasta hoy: el poder. Junto con ello, un método que, aunque exento de pretensiones sofisticadas de un micro empirismo, establece un fructífero campo de la comparación sociohistórica, combinando hábilmente la teoría política con la historia de forma novedosa. El realismo objetivista de Maquiavelo le hacen merecedor, tal vez de forma exagerada, de la paternidad de una tradición de estudio objetivo y científico de la política. Sin querer desmerecer esta relevancia, ¿qué diríamos de los aportes de Aristóteles para objetivar los regímenes políticos? Pensar que la obra de Maquiavelo está desprovista de toda reflexión normativa a diferencia de la de Aristóteles, sería ir demasiado lejos para la manera de pensar de Maquiavelo. Su obra no se agota en el realismo político y autores de tan distintas orientaciones como Gramsci (1949) y Strauss (1958) han propuesto ir más allá.

Gramsci (1949) considera que Maquiavelo es el primer filósofo de la práctica de la acción política y su visión tiene aspectos que no pueden simplificarse en el uso racional de la fuerza. En Maquiavelo (1532|2006) hay una reflexión mayor sobre el cambio político y la necesidad de que un jefe y estratega liderara la formación y consolidación del Estado italiano de aquella época. Gramsci observa en esta obra la base de la figura del partido político moderno y revolucionario que instauraría una nueva forma de Estado. Por su parte, Strauss (1958) identifica en Maquiavelo al hombre que rompe tanto con la tradición cristiana como con la filosofía política clásica y enseña a ver en él un adepto del hablar entre líneas. Debemos considerar el hecho de que Maquiavelo escribe después de haber sido encarcelado y torturado, y que quiere llamar la atención de los jóvenes florentinos evitando, a la vez, expresar sus visiones críticas de manera frontal. Por ello, se expresa de manera relativamente ambigua para que solo un pequeño número de lectores ilustrados lo entiendan. En este sentido y para entender su mensaje completo, tenemos que aprender a descifrar su ductus oblicus. 
Bataillon, G. (2020). Democracia, cambio político, e incertidumbre: Lefort al encuentro de Maquiavelo. Revista de Sociología, 35(1), 69-79. doi: 10.5354/0719-529X.2020.58109

La lectura de Lefort de Maquiavelo (1532 | 2006) se nutre de estas dos interpretaciones, pero es atenta a temáticas sumamente nuevas que contradicen en parte los comentarios de Gramsci (1949) y de Strauss (1958). Lefort (1972) plantea que, de cierta manera, Maquiavelo abre una nueva era en el pensamiento político. Esta nueva era de la "política sin lo político" surge a partir de una ruptura con la tradición cristiana de los escritos agustinos o de Tomás de Aquino y convencido de la necesidad de un retorno a los ejemplos de la Grecia antigua por medio de Aristóteles y de la República Romana con Cicerón. Para Lefort, Maquiavelo va incluso más lejos pues intenta explorar y renovar el pensamiento sobre las relaciones que constituyen el mundo político y lo hace con una impetuosidad jamás vista en ningún pensador antes que él.

Lefort y Maquiavelo en su contexto

Lefort comienza a escribir sus reflexiones políticas tempranamente a la edad de 24 años, primero al alero del fenomenólogo Maurice Merleau-Ponty en la revista LeS Temps Modernes que fundara junto a Jean Paul Sartre $\mathrm{y}$ en pequeñas revistas trotskistas antes de fundar Socialisme ou Barbarie junto a Cornelius Castoriadis desde donde desarrolló una fuerte crítica al totalitarismo soviético, proyecto que marcó fuertemente su carrera intelectual (Bataillon, 2014; Bataillon, 2019; Flynn, 2008; Poirier, 2020).

El acercamiento más profundo de Lefort hacia la obra de Maquiavelo se produce en 1954, período en el cual es invitado como profesor por la
Universidad de Sao Paulo. En ese momento Merleau-Ponty (editor de Les Temps Modernes) le pide hacer una recensión de las obras completas de Maquiavelo. Es así que Lefort empieza a releer a Maquiavelo y madura reflexiones durante casi veinte años. Estas forman parte de su tesis doctoral bajo la dirección de Raymond Aron. El mismo año se publicaría su libro sobre Maquiavelo (Lefort, 1972) en el que culmina una serie de reflexiones sobre la política y lo político desde la sociología, la antropología y debates con el marxismo. Conocer las circunstancias en las cuales Lefort escribe esta obra y el tiempo que le toma madurar sus reflexiones es relevante para pesar la densidad del contenido y permite relacionarla con las condiciones en las que el mismo Maquiavelo llegara a formular sus ideas. Maquiavelo terminó de escribir El Príncipe en 1513 a los 43 años de edad (el manuscrito fue publicado en 1532, cinco años después de la muerte del autor), teniendo a su haber cerca de veinte años de experiencia en asuntos públicos como secretario y funcionario de la Cancillería de la segunda República de Florencia. Redactaba informes de diversa naturaleza política y cumplió labores de embajador, conociendo de cerca los sucesos políticos de las ciudades italianas y sus pequeños príncipes y personajes como el polémico religioso dominico Girolamo Savonarola, con el cual libró una fuerte y conocida disputa que graficaba la confrontación de las visiones de la política en la modernidad contra los principios religiosos medievales que se resistían a morir. Su experiencia internacional le llevó a conocer bastante bien la monarquía francesa y alemana, llegando a ser considerado 
un excelente diplomático y un alto consejero de Estado. Para su mala fortuna, cuando Florencia pasa a manos de los Médici y se pone fin a la República, Maquiavelo es llevado a prisión siendo considerado un hombre peligroso. Tras su liberación es relegado a la periferia de Florencia donde, retirado de la vida de la ciudad, escribe la obra que le dará mayor fama, aunque de manera póstuma.

En un período relativamente breve, Maquiavelo organizó una serie de pensamientos que había madurado durante al menos una década. Su obra El Principe no es un ensayo circunstancial que escribe para poder obtener algún favor político, como muchos lo han querido deducir de su dedicatoria a Lorenzo de Médici. Por el contrario, escribe cosas fundamentales para la comprensión de la política, pero que desarrolló más profundamente en su obra dedicada a comentar la historia de Roma de Tito Livio (ver Maquiavelo, 1532| 1985).

En la carta escrita en diciembre de 1513 a su amigo Francesco Vettori (Barincou, 1955), Maquiavelo cuenta su vida cotidiana llena de anécdotas mundanas con lugareños, gente común con los cuales comparte, ríe y se pelea, pero que le permiten captar la forma que tiene el pueblo de ver la realidad. Luego de un día cualquiera de labores mundanas, Maquiavelo reserva para la noche el trabajo intelectual y revela: Cuando llega la noche, regreso a mi casa y me dirijo a mi estudio, donde justo antes de entrar me quito la ropa sucia de fango y lodo que he usado durante todo el día y me visto con nobles y curiales ropajes. Entonces, dignamente ataviado, ingreso en las antiguas cortes de los hombres de la antigüedad, donde recibido amablemente por ellos, me deleito con ese alimento que solo es mío, y para el que yo he nacido (Cartas de Maquiavelo [1513] en Barincou, 1955, p.369 [versión original en francés]).

Señala además en dicha carta el objetivo central de su trabajo: (...) he compuesto el opúsculo $D e$ Principatibus, donde desarrollo con toda la precisión de la que soy capaz este tema, exponiendo qué es un principado, de cuántas clases son, cómo se instauran, cómo se mantienen y por qué causa se pierden (Cartas de Maquiavelo [1513] en Barincou, 1955, p.370 [versión original en francés]).

\section{Lefort lector de El Príncipe}

Lefort (1972) señala que desde las primeras líneas de El Príncipe se puede advertir uno de los elementos fundamentales del pensamiento de Maquiavelo donde resalta lo factual alejado del juicio moral. En efecto, en Maquiavelo (1532 | 2006) no hay referencia religiosa alguna que sirva como lección, más bien las lecciones de religión son consideradas totalmente vanas para los fundamentos del poder. Por otra parte, y no menos importante, es el hecho que Maquiavelo se emplaza como un autor original y aventurado a pensar y constatar por sí mismo las formas del poder. Un elemento de la obra de Maquiavelo que influyó fuertemente en Lefort es su profunda vocación analítica empírica sobre hechos concretos, combinada de manera perfecta con una vocación filosófica que pretende discutir la construcción de la realidad del mundo político que lo rodea, alejado de cualquier tradición. En efecto, Maquiavelo desea reflexionar autónomamente 
Bataillon, G. (2020). Democracia, cambio político, e incertidumbre: Lefort al encuentro de Maquiavelo. Revista de Sociología, 35(1), 69-79. doi: 10.5354/0719-529X.2020.58109

a partir de los hechos sin saber necesariamente a dónde va a llegar. Su reflexión sobre la política y la soberanía supone partir de un lugar indeterminado para llegar a un lugar aún más indeterminado, lo que lo constituye en sujeto político y filósofo es su capacidad de cuestionarlo todo.

Tal como se puede apreciar en trabajos biográficos sobre Maquiavelo, como los de Pasquale (1953) y Gaille (2005), Maquiavelo parece tener una obsesión particular con dos cosas. Por una parte, aborrece las decisiones a medias y la falta de determinación de los gobernantes, lo que se aprecia en sus primeros capítulos en la descripción sobre los tipos de principados y la forma en la cual se pierde el poder sobre ellos (Maquiavelo 1532 |2006). Por otro lado, en la obra hay un deseo de mostrar el fuerte rol de la coerción en la configuración del orden político. Para Maquiavelo toda sabiduría debe ser respaldada con la potencia militar: las buenas leyes no sirven si no hay buenas armas para hacerlas cumplir o respetar lo pactado. Muchos lectores buscando tesis simplistas y unívocas han hecho de estas consideraciones las bases del realismo y del cinismo maquiavélico. Por el contrario, lo que le llama la atención a Lefort (1972) es cómo este pseudo-realismo es un señuelo y que Maquiavelo en realidad invita a explorar cosas diferentes más profundas.

El poder, una relación social circunstancial

Para Lefort (1972), la autoridad en Maquiavelo (i.e., la capacidad de algunos hombres de dominar a otros) dependía de las circunstancias. No existe la autoridad con una legitimidad intrínsecamente dada o ganada de una vez y para siempre. No importa cuál sea su origen, la autoridad y la manera en la cuál se ejerce y se mantiene su carácter es siempre circunstancial. En este sentido, Maquiavelo retoma de cierta manera una idea de los antiguos como Platón, Aristóteles y Tucídides, sobre la concepción de la politeia como una forma política caracterizada por la coexistencia y la síntesis de la pluralidad de las expresiones de la vida humana, donde se combinan el mundo de la política con el de la intimidad de la familia, el arte, el trabajo, etc. Para Maquiavelo todo esto forma parte del carácter de una ciudad-Estado y ciertamente de la manera en la cual se ejerce el poder.

Es la misma idea que desarrolló a su manera Tocqueville (1835 | 2001) al señalar que la democracia amolda, renueva y transforma los vínculos familiares, así como las relaciones entre servidor y amo. De manera similar, en su descripción de los diferentes tipos de principados, Maquiavelo (1532| 2006) desarrolla la idea de que no hay una esencia estática de la sociedad, sino una manera de ser temporal que aparece como sinónimo de grandeza y aspiraciones para todos, que se relacionan al mismo tiempo con un interés general y con intereses particulares de las coyunturas. El político virtuoso es quien tiene la capacidad de conciliar intereses, de ponerse por encima de las facciones, y dar esperanzas a todos de un bien común compartido, de ser parte de una historia común. En sintonía con esta idea, Touraine (1961) se refiere al régimen de historicidad del siglo XIX como la concepción de un desarrollo industrial que favorecía a todos e incluía la aspiración de una conciliación entre el capital y 
Bataillon, G. (2020). Democracia, cambio político, e incertidumbre: Lefort al encuentro de Maquiavelo. Revista de Sociología, 35(1), 69-79. doi: 10.5354/0719-529X.2020.58109

el proletariado por el hecho de estar en un mismo tren histórico. La idea de Maquiavelo es que el buen príncipe, es aquel que es capaz de moderar las pasiones, pero que no lo hace solo por el gusto por la moderación o por conformidad a las enseñanzas de Cristo, sino que las modera para que una sociedad pueda tomar forma basada en el reconocimiento del otro, más allá de los apetitos, del reconocimiento del otro como un semejante. Esta es una idea que Lefort recogió y que influyó de manera importante en el desarrollo de su obra al comprender la democracia como una experiencia social más allá del gobierno, como una forma de vida en comunidad (Bataillon, 2014; Poirier, 2015).

Maquiavelo (1532|2006) describió la política como una guerra y una guerra muy cruel, entre facciones, ciudades, entre príncipes, que quieren anexar otros reinos más pequeños, etc. Más allá de esto, el poder aparece como un estilo de relaciones de dominación, de orden, que se extiende hacia todo ámbito de la sociedad. La cuestión de la estabilidad del Estado no depende solo de la vigencia del poder del príncipe, sino que está fundada en la relación con sus súbditos o el popolo minore. A diferencia de filósofos como Aristóteles -que veía para cada forma pura de gobierno una degeneración en alguna forma corrupta en razón del actuar de los gobernantespara Maquiavelo una forma de gobierno, en su dimensión más amplia, tiene que ver con una forma de dominación aceptada y que tiene una correspondencia en un tipo de relación social formada a lo largo del tiempo. De igual manera, la autoridad no está solamente limitada por las leyes, sino que se considera la importancia de un intercambio entre gobernantes y gobernados, más allá de lo estrictamente legal.

Maquiavelo hace una descripción del comportamiento de diversos gobernantes del Antiguo Testamento como Moisés, o príncipes de la antigüedad en Persia, Grecia y Roma. En ello, Lefort constata un bougé, un deslice, entre el príncipe y su imagen, enfatizando que este deslice es fundamental en política (Lefort, 1972). Si bien los actos de un príncipe determinan el curso del gobierno, todo resultado debe ser pensado como la consecuencia de una relación ambigua entre sus súbditos y él. Ya no hay una idea de lo bueno o lo posible según la moderación de quien gobierna conforme a las normas. En el ejemplo del gobierno de Moisés (Maquiavelo, 1532|2006) señala que lo más importante en su gobierno es su relación con el pueblo judío y cómo es percibido por él, antes que su condición de elegido de Dios. En efecto, cuando Moisés rompe las Tablas de la Ley que Dios le otorgó, lo hace en el fondo para salvar y fundar su comunidad: fue un capitán astuto que supo decidir pragmáticamente en su momento a favor de su pueblo.

Los humores contrapuestos y el conflicto

Maquiavelo presenta como algo natural que el orden de las cosas sea cambiante, dada la constante "oposición de humores" entre los súbditos y los príncipes de toda índole. Quien desee entender la política debe asumir esta continua oposición de humores y ver en ella la dinámica del cambio social. Es así que, la legitimidad para Maquiavelo no viene dada por un orden exterior a los hombres al cual hay que conformarse según 
Bataillon, G. (2020). Democracia, cambio político, e incertidumbre: Lefort al encuentro de Maquiavelo. Revista de Sociología, 35(1), 69-79. doi: 10.5354/0719-529X.2020.58109

la moral, si no que en cada momento los actores están en constante pugna con sus deseos y sus furias configurando las dinámicas del poder y la legitimidad. Una especie de caos aparece en Maquiavelo como la naturaleza de las cosas guiada por la fortuna, frente a la cual un político talentoso sabe imponerse porque comprende esta naturaleza cambiante y acepta enfrentar el desafío de gobernar en la incertidumbre.

Particularmente respecto al principado civil (i.e., aquel que se obtiene no por crímenes ni violencia, sino que por el favor de los compatriotas), Maquiavelo (1532|2006) sostiene que estos dos humores se encuentran claramente contrapuestos y derivan, por un lado, del deseo de los poderosos de dominar y oprimir al pueblo y, por otro lado, de los deseos del pueblo que se resiste a la dominación y la opresión. Para Maquiavelo esta tensión es fecunda y contiene el campo de fuerzas generadoras de un cierto equilibrio. En oposición al pensamiento clásico y medieval (que defiende el control de las pasiones y lleva a la moderación) Maquiavelo ve en ello la naturaleza humana fuera de todo idealismo, mucho antes que Hobbes (Lefort, 1972) y con una importante diferencia: bajo una aparente guerra de todos contra todos, puede existir un equilibrio entre los apetitos que se produce mediante el buen gobierno.

Puede que los príncipes construyan su imagen sobre a idea de que pueden crear un equilibrio que permita superar la oposición sin concesión entre el popolo minore y los grandes, pero se encumbran como portadores de un interés general y ganan el apoyo del pueblo para controlar a los grandes. Así, se abre la posibilidad de que el príncipe, en defensa del pueblo, se transforme en su enemigo. No habría que hacerse ilusiones al respecto: el poder siempre termina volviéndose contra el pueblo y este conflicto social es insoluble. De esta forma, para Lefort, Maquiavelo es el primero en dar al conflicto y a las pasiones un rol fundamental en el orden político. Sin embargo, no lo planteó desde una cierta dialéctica como lo hicieron Guizot (1843|1985) o Marx (1848) como la lucha de clases entre el proletariado y la burguesía. En efecto, en el planteamiento dialéctico de Marx hay un momento y una aspiración a terminar con dicho conflicto bajo un nuevo régimen sin clases sociales (Lefort, 1972, 1986). Nada más alejado de la visión de Maquiavelo quien consideró que esta es una experiencia insuperable en la historia. Para Maquiavelo las clases existen en confrontación de sus deseos y pasiones, pero esta lucha abre la posibilidad de una cooperación, donde el arte de la política consiste en saber situarse entre estos intereses humanos en pugna para fundar un orden social. No obstante, esto ocurre sin ninguna garantía externa: son los hombres y el príncipe quienes son capaces de determinarlo.

Esta es una idea importante que desarrolló en el capítulo IV de los Discursos (ver Maquiavelo 1532 1985), dirigido a los jóvenes florentinos para convencerles que la grandeza de Roma no estaba en el Senado como institución, sino en los pleitos en su seno y que la República era capaz de aceptar que éstos fuesen expuestos y formaran parte cotidiana de la vida política, lo cual se puede ejemplificar con el siguiente pasaje:

Sostengo que quienes condenan los conflictos entre la nobleza y el pueblo, condenan lo que fue la primera causa de la libertad de Roma, teniendo más en cuenta los tumultos y 
Bataillon, G. (2020). Democracia, cambio político, e incertidumbre: Lefort al encuentro de Maquiavelo. Revista de Sociología, 35(1), 69-79. doi: 10.5354/0719-529X.2020.58109

desórdenes ocurridos que los buenos ejemplos que éstos produjeron (...) de ninguna manera se debe llamar desordenada a una república donde hubo tantos ejemplos de virtud; porque los buenos ejemplos nacen de la buena educación de las buena leyes, y éstas de aquellos desórdenes que muchos de manera desconsiderada condenan (p. 44).

La fuerza y la novedad en esta visión de Maquiavelo radica en aquello que Lefort (1972) denominó lo "todavía no pensado" (p. 384). Maquiavelo describió de manera nueva la vida pasada y contemporánea de los hombres y esta descripción permite pensar el futuro. El autor deseaba que Florencia no fuera una tiranía y que Italia no fuera despedazada por partidos extranjeros que se coluden con algunas ciudades para oprimir a sus pueblos. Maquiavelo quería, a fin de cuentas, promover un orden político deseable. En todos los ejemplos que da para mostrar lo deseable o justo se basa en hechos empíricos contra toda visión moral del bien. Las acciones orientadas al bien son aquellas que tienden a los buenos resultados para toda la sociedad, no únicamente para el príncipe, un punto en general mal comprendido por los intérpretes del maquiavelismo político (Lefort, 1972). Con todo, el mismo Lefort señalaría el rol de la obra de Maquiavelo en su pensamiento en algo que es importante considerar:

De paso aclaro que en ninguna parte erijo a Maquiavelo en maestro ni llamo a seguir lo que sería su enseñanza. Mi convicción, al mismo tiempo, es que su experiencia y la nuestra no se superponen, y que la senda que él abre no está totalmente a nuestras espaldas, que no se terminó de explorarla, que en un sentido todavía está delante de nosotros (Lefort, 2014, p.164).

\section{CONCLUSIONES}

Las ideas de Maquiavelo que retoma Lefort $(1972,1986,1992,1997)$, anuncian en gran parte las reflexiones sobre la igualdad que aparecen con la revolución inglesa, aunque de manera más resonante con la revolución norteamericana (también conocida como la guerra de la independencia de Estados Unidos de Norteamérica) o la Declaración de los Derechos del Hombre y el Ciudadano tras la revolución francesa: las personas nacen iguales. Lo que resulta muy llamativo es que Lefort, de cierta manera, a partir de sus reflexiones sobre la burocracia y el totalitarismo, se vuelve más sensible a la idea sugerida por
Maquiavelo de una lucha de clases insuperable. La experiencia -ya sea del bonapartismo después de la revolución francesa, del leninismo o del estalinismo- indican que un gobernante o un partido que dice representar al popolo minore o los explotados, y que ha logrado controlar el poder de los grandes anulando los conflictos de clase, puede construirse en una nueva y peligrosa forma dominación pretendiendo la unidad social en alguna forma de totalitarismo. Hoy pocos tienen la lucidez de Maquiavelo. Hay quienes creen en la posibilidad de una sociedad reconciliada sin clases o creen en mecanismos de 
mercado que puedan regular y suprimir estas tensiones. Llama particularmente la atención la ilusión neoliberal de pensar que el funcionamiento del mercado va a solucionar esta cuestión de los apetitos opuestos entre los grupos sociales. Por otra parte, quienes piensan que el juego político -ya sea bajo la forma de partidos políticos o asambleas populares o cualquier forma de participación institucional- puede de cierta manera simplificar las pugnas, caen bajo el juicio de Maquiavelo en un velo de total ingenuidad. Las ideas de Maquiavelo niegan completamente esta posibilidad de conciliación perpetua. Más vale saber de antemano que las relaciones políticas entre los seres humanos son brutales, pero que en la confrontación hay una cierta fecundidad.

Todas las ideas de Maquiavelo sobre la política como el arte de enfrentar y desafiar la aventura humana anuncian las reflexiones sobre la esencia de la democracia. Reflexiones con las cuales Lefort conecta estrechamente. Para Lefort la democracia se caracteriza por dos cosas. La primera es la democracia como un régimen de incertidumbre generalizada. Si todas las personas nacen iguales, entonces todo es cuestionable. No hay ninguna autoridad legítima que pueda evitar el cuestionamiento. El más humilde puede desafiar al más sabio para interpelar la realidad y llegar a una solución correcta. En segundo lugar, está la idea del poder como un lugar vacío, que no pertenece a nadie. Lefort señala que los acuerdos para su titularidad son temporales, al igual que los gobernantes quienes deben respetar a las minorías el derecho a una interrelación conflictual sobre los fines de la sociedad. Esta teoría de Lefort está en su germen en Maquiavelo y es por ello que la obra de Lefort es de difícil y compleja lectura, aunque vale la pena el esfuerzo. Hay en él muchas pistas para pensar el presente, sobre todo si consideramos que Lefort se lanzó en un trabajo de erudición de casi dos décadas.

Su monumental trabajo se valida porque permite dar luces para pensar y actuar en los tiempos presentes e inspirar la tarea de los científicos sociales que, para Lefort (1992), debiese ser pensar el mundo actual para actuar en el de la manera más acertada.

\section{REFERENCIAS}

Aron, R. (1993). Machiavel et les tyrannies modernes. París, Francia: Éditions de Fallois.

Bataillon, G. (2014). Claude Lefort, pratique et pensée de la désincorporation. Raisons politiques, 56(4), 69-85. doi: 10.3917/rai.056.0069
Bataillon, G. (2019). Claude Lefort, pensador de lo político. Nueva Sociedad, 281(1), 152-163. Recuperado de https://nuso.org/media/articles/downloads/EN_ Bataillon_281.pdf 
Barbuto, M. (Ed.). (2017). Problematizing II Principe. Barcelona, España: Edicions de la Universitat de Barcelona.

Barincou, E. (1955). Toutes les lettres de Machiavel. París, Francia: Éditions Gallimard.

Flynn, B. (2008). Lefort y lo político. Buenos Aires, Argentina: Prometeo Libros.

Gaille, M. (2005). Machiavel. París, Francia: Éditions Tallandier.

Gramsci, A. (1949). Note sul Machiavelli, sulla politica e sullo stato moderno. Turín, Italia: Giulio Einaudi Editore.

Guizot, F. (1843 | 1985). Histoire de la civilisation en Europe. París, Francia: Hachette Livre.

Lefort, C. (1972). Le travail de l'oeuvre Macqiavel. París, Francia: Éditions Gallimard.

Lefort, C. (1986). Essais sur le politique. XIX-XXe siècles. París, Francia: Éditions du Seuil.

Lefort, C. (1992). Écrire à l'épreuve du politique. París, Francia: Calmann-Lévi.

Lefort, C. (1997). L'imaginaire de la crise. Commentaire, $\quad 79(3), \quad 525-536 . \quad$ doi: 10.3917/comm.079.0525

Lefort, C. (2014). El pueblo y el poder. Buenos Aires, Argentina: Prometeo Editorial.

Marx, K. (1848). Manifest der kommunistischen partei. Londres, UK: Kommunistischer Arbeiterbildungsverein.
Maquiavelo, N. (1532|1985). Discours sur la première décade de Tite-Live. París, Francia: Editions Flammarion.

Maquiavelo, N. (1532|2006). El Príncipe. Madrid, España: Editorial Edaf.

Morgenthau, H, (1986). Politica entre las naciones. Buenos Aires, Argentina: Grupo Editor Latinoamericano (GEL).

Pasquale, V. (1953). Maquiavelo su vida y su tiempo. México D.F. : Biografías Gandesa.

Poirier, N. (2015). Cornelius castoriadis et Claude Lefort: L'experience democratique. Lormont: Le Bord de I'eau.

Poirier, N. (2020). Introduction à Claude Lefort. París, Francia: Éditions La Découverte.

Strauss, L. (1958). Thoughts on Machiavelli. Glencoe, IL: The Free Press.

Tocqueville, A. (1835|2001). La democracia en América. (Vol. 1). México D.F. : Fondo de Cultura Económica.

Touraine, A. (1961). Industrialisation et conscience ouvrière. Sociologie du Travail, 3(4), 77-95. doi: 10.3406/sotra.1961.1077

Manuscrito recibido: 03-04-2020 Manuscrito aceptado: 09-07-2020 